\title{
Alterations in microRNAs miR-21 and let-7a correlate with aberrant STAT3 signaling and downstream effects during cervical carcinogenesis
}

Gauri Shishodia 1,5,6, Shirish Shukla 1,7, Yogesh Srivastava', Shashank Masaldan ${ }^{1}$, Sumita Mehta ${ }^{4}$, Suresh Bhambhani ${ }^{2}$, Shashi Sharma ${ }^{3}$, Ravi Mehrotra ${ }^{2}$, Bhudev Chandra Das ${ }^{5}$ and Alok Chandra Bharti ${ }^{* *}$

\begin{abstract}
Background: Present study provides clinical evidence of existence of a functional loop involving miR-21 and let-7a as potential regulators of aberrant STAT3 signaling recently reported by our group in an experimental setup (Shishodia et al. BMC Cancer 2014, 14:996). The study is now extended to a set of cervical tissues that represent natural history of human papillomavirus (HPV)-induced tumorigenic transformation.
\end{abstract}

Materials and methods: Cervical tissues from histopathologically-confirmed pre-cancer (23) and cancer lesions (56) along with the normal control tissues (23) were examined for their HPV infection status, expression level of miR-21 \& let-7a and STAT3 \& PSTAT3 (Y705) by PCR-based genotyping, quantitative real-time PCR and immunoblotting.

Results: Analysis of cancer tissues revealed an elevated miR-21 and reduced let-7a expression that correspond to the level of STAT3 signaling. While miR-21 showed direct association, let-7a expression was inversely related to STAT3 expression and its activation. In contrast, a similar reciprocal expression kinetics was absent in LSIL and HSIL tissues which overexpressed let-7a. miR-21 was found differentially overexpressed in HPV16-positive lesions with a higher oncoprotein E6 level. Overexpression of miR-21 was accompanied by elevated level of other STAT3-regulated gene products MMP-2 and MMP-9. Enhanced miR-21 was found associated with decreased level of STAT3 negative regulator PTEN and negative regulator of MMPs, TIMP-3.

Conclusion: Overall, our study suggests that the microRNAs, miR-21 and let-7a function as clinically relevant integral components of STAT3 signaling and are responsible for maintaining activated state of STAT3 in HPV-infected cells during cervical carcinogenesis.

Keywords: HPV, LSIL, HSIL, Cervical cancer, STAT3, pSTAT3, miR-21, let-7a, MMPs, PTEN, TIMP-3

\section{Introduction}

Recent observations from our laboratory $[1,2]$ and others $[3,4]$ indicate involvement of an aberrantly expressed and constitutively active STAT3 in cervical carcinogenesis and its level increases with progression of disease in HPV16infected cervical lesions. Aberrant activation of STAT3 has been strongly implicated in epithelial transformation [5] and plays a functional role in HPV16-induced cervical carcinogenesis [6]. Aberrant STAT3 signaling has therefore

\footnotetext{
* Correspondence: alokchandrab@yahoo.com

${ }^{1}$ Division of Molecular Oncology, Institute of Cytology and Preventive Oncology, I - 7, Sector -39, Noida 201301, Uttar Pradesh, India

Full list of author information is available at the end of the article
}

been emerging as a key cellular event that links chronic inflammation to cancer [7] and frequently reported in majority of cancers $[8,9]$. However, the cellular events responsible for constitutively active STAT3 signaling and modulation of its downstream cellular effects remained a poorly-defined area and demanded better understanding for its effective therapeutic targeting. Although there are a number of positive and negative protein regulators that control expression and activity of STAT3, recent studies implicate involvement of microRNAs in controlling STAT proteins/activity and the downstream targets of STAT3 as well [10]. Considering the broad spectrum of these downstream targets, miRNAs are increasingly gaining attention as a class of prime regulators or 'tuners' of biological 
response. However, a clinical evidence of miRNAs interacting with aberrant STAT3 signaling in general and cervical carcinogenesis in particular is currently lacking.

Altered expression of multiple miRNAs has been reported in HPV-positive cervical cancer cells [11-14]. Among oncogenically-relevant miRNAs that could potentially impact STAT3 signaling, we examined involvement of miR-21 and let-7a experimentally [15]. The upstream enhancer of miR-21 gene was found to contain two STAT3 binding sites that are strictly conserved. Interestingly, miR- 21 is located in the fragile site FRA17B region, which is also one of the HPV16 integration loci at $17 \mathrm{q} 23.2$ [16]. miR-21 has been found to control apoptosis, cell proliferation, and cell migration in breast, colorectal, and other cancers [17-20]. Aberrantly expressed miR-21 has recently been proposed in cervical carcinogenesis as well [21-25]. Similarly, assessment of STAT3 transcript as miR target revealed let-7a as an important regulator of STAT3 level [26]. Let-7a is often decreased in cancer cells through chromosomal deletion $[27,28]$. Ectopic Let-7a expression indirectly represses STAT3 transcription through its binding to the 3'-UTR of IL-6, which is a major STAT3-inducing, carcinogenicallyrelevant cytokine [7]. Moreover, STAT3 has been reported as direct cellular target of let-7a [26]. Our observations strongly indicated a functional implication of altering levels of either miR-21, let-7a or STAT3 signaling on each other in cervical cancer cell lines and the loop was found controlled by HPV oncoprotein E6 in in vitro studies [15]. However, the clinical correlates of such an operational loop in tumor tissues are yet to be established.

Furthermore, STAT3 which is activated primarily through phosphorylation at Tyr705 residue [29] controls MMP expression and activity, and thus plays a pivotal role in invasion and metastasis during cervical cancer $[30,31]$. STAT3 upregulates activity of both promoters of MMPs and tissue inhibitors of MMPs (TIMPs) which are considered as major molecular mediators responsible for malignant switching of tumors [32-35]. However, how these events are mechanistically regulated and involvement, if any, of microRNA in these events is poorly understood.

In view of the above, we evaluated the expression level of miR-21 and let-7a and examined their association with level of STAT3 and active STAT3 (pSTAT3 Tyr705) in different grades of cervical tissues derived from precancer (diagnosed and categorized by cytology as LSIL and HSIL) and cancer lesions that represent natural history of HPV-induced cervical carcinogenesis. Concurrently, we examined the status of their HPV infection (genotypes and HPVE6) and level of downstream targets of STAT3 (MMP-2 and MMP-9) and miR-21 (TIMP-3 and PTEN).

\section{Materials and method}

\section{Cell lines and clinical specimens}

Cervical cancer cell lines C33a (HPV-negative), CaSki and $\mathrm{SiHa}$ (HPV16-positive) and HeLa (HPV18-positive) were procured from ATCC and were maintained in prescribed culture conditions. A total of 102 fresh cervical tissue biopsies were collected comprising 56 malignant; 23 premalignant and 23 non-malignant control tissues (comprising 3 normal and 20 tissues with cervicitis) prior to any chemo/radio therapy from the Cancer Clinic, Gynae OPDs of Lok Nayak Hospital and Guru Teg Bahadur Hospital, Delhi, India respectively. Written informed consent and clinico-epidemiological details (Table 1) were taken from their clinical records. Each tissue designated for molecular analysis was collected in cold $1 \times$ phosphate buffer saline (PBS) and was immediately trifurcated to isolate and assayed DNA, RNA and proteins by methods described below. All reagents used in the study were of analytical or molecular biology grade and procured from Sigma Aldrich (St Louis, MO, USA) whereas primary and secondary antibodies and ECL kit were purchased from Santa Cruz Biotechnology (Santa Cruz Biotechnology Inc., Texas, USA) unless specified.

\section{Ethics, consent and permissions}

Institutional Academic and Ethical Committee of Guru Teg Bahadur Hospital approved the study vide sanction no F.No. Mem.Sec./Ethical Comm/2011/3752-62 dated $16 / 03 / 2011$. Written informed consent was obtained from all the study subjects and was carried out in accordance with the principles of the Helsinki Declaration.

\section{Isolation of DNA and diagnosis of HPV infection}

Genomic DNA from cervical cancer cell lines and from cervical cancer tissues was isolated from clinical samples by the standard phenol-chloroform extraction procedure $[1,36]$. Briefly, the method involved fine mincing of fresh tissue in cold 1X PBS with surgical blade in petridish on ice. The minced tissue material was collected in $1.5 \mathrm{ml}$ tube and centrifuged at $3000 \mathrm{rpm}$ for $5 \mathrm{~min}$. after centrifugation the PBS was discarded and minced tissue material was then immediately suspended in $0.4 \mathrm{ml} \mathrm{TE}$ (10 mM Tris- $\mathrm{HCl}+1 \mathrm{mM}$ EDTA, $\mathrm{pH}$ 8.0). To this suspension $0.2 \mathrm{ml}$ lysis buffer ( $3 \%$ SDS in 2xTE, $\mathrm{pH} 8.0$ ) and Proteinase K (Roche, Basel, Germany) at $100 \mu \mathrm{g} / \mathrm{ml}$ was added. The lysate was carefully mixed avoiding froth formation and incubated overnight at $50{ }^{\circ} \mathrm{C}$. Next day equal volume $(0.6 \mathrm{ml})$ of phenol (Merck Chemicals, Darmstadt, Germany) (Tris-equilibrated, $\mathrm{pH}$ 8.0) was added to the lysate and allowed to mix on an overhead shaker for $15 \mathrm{~min}$. This was followed by a centrifugation at $6000 \mathrm{rpm}$ for $10 \mathrm{~min}$ leading to the separation of two distinct layers. The upper aqueous phase was carefully 
Table 1 Clinico-pathological characteristics of cervical specimens and PCR-based analysis of their genomic DNA for HPV infection and genotype analysis

\begin{tabular}{|c|c|c|c|c|c|c|c|}
\hline Tissue type & Characteristics & $\begin{array}{l}\text { Number of } \\
\text { samples }\end{array}$ & $\begin{array}{l}\text { Total HPV+ (HPV L1) } \\
\text { (n/\%age) }\end{array}$ & $\begin{array}{l}\text { HPV } 16 \\
\text { (n/\%age) }\end{array}$ & $\begin{array}{l}\text { HPV18 } \\
\text { (n/\%age) }\end{array}$ & $\begin{array}{l}\text { Others HPV } \\
\text { (n/\%age) }\end{array}$ & $\begin{array}{l}\text { Multiple } \\
\text { infections } \\
\end{array}$ \\
\hline \multirow[t]{3}{*}{ Normal/Control } & & 23 & $1(4.3 \%)$ & $1(4.3 \%)$ & - & - & - \\
\hline & Cytolgically normal & 3 & - & - & - & - & - \\
\hline & Cervicitis & 20 & $1(5 \%)$ & $1(5 \%)$ & - & - & - \\
\hline \multirow[t]{3}{*}{ Pre-cancer } & & 23 & $14(61 \%)$ & $12(52 \%)$ & 1 (4.3\%) & 0 & - \\
\hline & LSIL & 10 & $5(50 \%)$ & $4(40 \%)$ & 0 & 0 & - \\
\hline & HSIL & 13 & 9 (69 \%) & $8(62 \%)$ & $1(7.7 \%)$ & 0 & - \\
\hline \multirow[t]{2}{*}{ Cancer Tissues } & & 56 & $53(95 \%)$ & 44 (79 \%) & $6(11 \%)$ & $4(7.1 \%)$ & $5(9 \%)$ \\
\hline & & $44^{\mathrm{a}}$ & 39 (88.7 \%) & $33(75 \%)$ & $6(13.7 \%)$ & $1(2.3 \%)$ & $5(11.3 \%)$ \\
\hline \multirow[t]{4}{*}{ Histopathological grading } & WDSCC & 16 & 15 (94 \%) & 12 (75 \%) & $2(13 \%)$ & 0 & $2(13 \%)$ \\
\hline & MDSCC & 14 & $10(71.4 \%)$ & $10(71.4 \%)$ & $1(7 \%)$ & $1(7 \%)$ & 0 \\
\hline & PDSCC & 14 & $14(100 \%)$ & $11(79 \%)$ & $3(21 \%)$ & 0 & $3(21 \%)$ \\
\hline & & $52^{\mathrm{a}}$ & $48(92 \%)$ & $42(81 \%)$ & $5(9.6 \%)$ & $4(7.7 \%)$ & $5(9.6 \%)$ \\
\hline \multirow[t]{4}{*}{ Clinical stages } & Stage I & 5 & $5(100 \%)$ & $5(100 \%)$ & 0 & 0 & 0 \\
\hline & Stage II & 17 & 15 (88 \%) & 14 (82 \%) & $2(12 \%)$ & $1(6 \%)$ & $1(6 \%)$ \\
\hline & Stage III & 26 & 24 (92 \%) & 19 (73 \%) & $3(11.5 \%)$ & $1(4 \%)$ & $3(11.5 \%)$ \\
\hline & Stage IV & 4 & $4(100 \%)$ & $4(100 \%)$ & 0 & 2 (50 \%) & $1(25 \%)$ \\
\hline
\end{tabular}

HPV human papillomavirus, SCC squamous cell carcinoma, LSIL low grade squamous intraepithelial lesions, HSIL high grade squamous intraepithelial lesions,

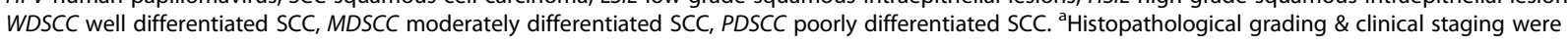
available for 44 and 52 samples respectively

transferred to a fresh, sterilized $1.5 \mathrm{ml}$ tube to which an equal volume of phenol and CIA (chloroform: iso-amyl alcohol [24:1]) (Qualigens fine chemicals, India) were added, mixed on an overhead shaker and centrifuged as in the previous step. The aqueous phase was transferred to a fresh $1.5 \mathrm{ml}$ tube. To this equal amount $(0.6 \mathrm{ml})$ of CIA was added, mixed and centrifuged. The upper aqueous layer was collected and DNA was precipitated overnight at $-20{ }^{\circ} \mathrm{C}$. Following additions of $1 / 10$ th volume of chilled $3 \mathrm{M}$ sodium acetate ( $\mathrm{pH}$ 5.2) and 2.5 volumes of chilled absolute ethanol (Merck Chemicals, Darmstadt, Germany), the precipitated DNA was precipitated out in a micro centrifuge tube and washed in $70 \%$ ethanol for removal of traces of salt. It was finally centrifuged at $12,000 \mathrm{rpm}$ for $5 \mathrm{~min}$ at room temperature to obtain a pellet of DNA which was vacuum dried and re-suspended in 1 xTE (pH 8.3), quantitated by UV spectrophotometry and stored at $-20{ }^{\circ} \mathrm{C}$. HPV diagnosis was performed by using a pair of consensus degenerate primers (MY09 and MY11) (Table 2). PCR was performed in a $25 \mu \mathrm{l}$ reaction mixture containing $100 \mathrm{ng}$ DNA, $10 \mathrm{mM}$ Tris- $\mathrm{HCl}$ (pH 8.4), $50 \mathrm{mM} \mathrm{KCl}, 1.5 \mathrm{mM} \mathrm{MgCl} 2,125 \mathrm{mM}$ of each dNTPs (MBI fermentas, Ontario, Canada), 5pmol of oligonucleotide primers and 0.5U Taq DNA polymerase. The temperature profile used for amplification constituted an initial denaturation at $95{ }^{\circ} \mathrm{C}$ for $4 \mathrm{~min}$ followed by 30 cycles of denaturation at $95{ }^{\circ} \mathrm{C}$ for $30 \mathrm{~s}$, annealing at $55^{\circ} \mathrm{C}$ for $30 \mathrm{~s}$ and extension at $72{ }^{\circ} \mathrm{C}$ for $1 \mathrm{~min}$, which was extended for $5 \mathrm{~min}$ at the final cycle. HPV positive samples were subjected to comprehensive HPV genotyping by PGMY-Reverse Line Blot which can detect about $32 \mathrm{HPV}$ types including all high-risk and low-risk types [37].

Table 2 List of primers used for HPV infection, HPV typing, STAT3 RT PCR and quality control of RNA ${ }^{a}$

\begin{tabular}{|c|c|c|}
\hline Primers & Amplicon size & Primer sequence \\
\hline MY09/MY11 $\beta$-Globin & $450 \mathrm{bp} 268 \mathrm{bp}$ & $\begin{array}{l}\text { 5'- GCM CAG GGW CAT AAY AAT GG -3' 5'- CGT CCM ARR GGA WAC TGA -3' Where } M=A \text { or C, } \\
\text { W=A or T, Y = C or T and R=A or G 5'- GAA GAG CCA AGG ACA GGT AC-3' } \\
5^{\prime}-\text { CAA CTT CAT CCA CGT TAC ACC-3' }\end{array}$ \\
\hline HPV16 & $217 \mathrm{bp}$ & 5'- AAG GCC AAC TAA ATG TCA C -3' 5'- CTG CTT TTA TAC TAA CCG G -3' \\
\hline HPV18 & $322 \mathrm{bp}$ & 5'- ACC TTA ATG AAA AAC CAC GA -3' 5'- CGT CGT TTA GAG TGG TTC GTG -3' \\
\hline STAT3 RT & $318 \mathrm{bp}$ & 5'-TTGCCAGTTGTGGTGATC-3' 5'-GAACCCAGAAGGAGAAGC-3' \\
\hline GAPDH RT & $322 \mathrm{bp}$ & 5'-TGGATATTGTTGCCATCA ATGACC-3' 5'-GATGGCATGGACTGTGGTCATG-3' \\
\hline
\end{tabular}

${ }^{a}$ List of primers and probes for $P G M Y$ reverse line blot-based comprehensive genotyping and the methodology can be obtained through WHO HPV laboratory manual (First Edition; 2010) 
Infection of HPV16 and HPV18 type was validated using type-specific PCRs as described earlier [1]. Beta-globin amplification was done as internal control. Customsynthesized, HPLC-purified primers were procured from M/s Microsynth (Germany) or M/s Eurogentec (Belgium).

\section{Isolation of total RNA and amplification of microRNAs by real time-PCR (RT-PCR)}

Total RNA from cell lines and clinical samples was extracted using mirVana miRNA isolation kit (Ambion, Austin, USA) as per the manufacturer's instructions. Briefly, the method involves first to lyse the sample in a denaturing lysis solution which stabilizes RNA and inactivates RNases. The lysate is then extracted once with Acid-Phenol: Chloroform which removes most of the other cellular components, leaving a semi-pure RNA sample. This is further purified over a glass-fiber filter. microRNAs expression was checked by using mirVana qRT-PCR kit and miR-21 and let-7a specific primers (Ambion, Austin, USA) as per the kit protocol (Table 3). First RT PCR was performed in a $10 \mu \mathrm{l}$ reaction mixture containing 20 ng RNA, 1X mirVana RT buffer, 1X mirVana RT primer and ArrayScript enzyme mix. The temperature profile used for amplification constituted an initial incubation at $37^{\circ} \mathrm{C}$ for $30 \mathrm{~min}$ followed by $10 \mathrm{~min}$ incubation at $95{ }^{\circ} \mathrm{C}$ to inactivate the ArrayScript. Then real time PCR was performed in a $10 \mu$ reaction mixture using $2 \mu \mathrm{l}$ of the cDNA prepared in previous reaction, SYBR Green and mirVana PCR Primers. The temperature profile used for amplification constituted an initial denaturation at $95^{\circ} \mathrm{C}$ for 3 min followed by 40 cycles of denaturation at $95{ }^{\circ} \mathrm{C}$ for $15 \mathrm{~s}$ and annealing at $60{ }^{\circ} \mathrm{C}$ for $30 \mathrm{~s}$. PCR was performed using BioRad iCycler real-time PCR (BioRad, USA). U6 RNA (Ambion, Austin, USA) was used for normalization. Data were expressed as fold change $\left(2^{-\Delta \Delta C t}\right)$ with respect to pooled reference microRNA prepared from equal amount of 3 non-malignant normal, HPV-negative control tissues. Primers used for
miR expression analysis were procured from Dharmacon, USA.

\section{Isolation of total proteins from cervical cell lines and tissues and immunoblotting}

Total proteins from cervical cancer cell lines and cervical tissue biopsies were prepared by the method described previously [38]. Briefly, the minced tissue material or different cell lines $\left(2 \times 10^{6}\right.$ cells $)$ was centrifuged at $4,000 \mathrm{rpm}$ at $4{ }^{\circ} \mathrm{C}$ to wash off $1 \mathrm{x}$ PBS solution. For preparation of total proteins, the pellet was resuspended in lysis buffer $[20 \mathrm{mM}$ Tris $(\mathrm{pH} 7.4), 250 \mathrm{mM} \mathrm{NaCl}$, $2 \mathrm{mM}$ EDTA (pH 8.0), $0.1 \%$ Triton X-100, $0.01 \mathrm{mg} / \mathrm{ml}$ aprotinin, $0.005 \mathrm{mg} / \mathrm{ml}$ leupeptin, $0.4 \mathrm{mM}$ PMSF, and $4 \mathrm{mM} \mathrm{Na}_{3} \mathrm{VO}_{4}$ ]. Lysates were spun at $14,000 \mathrm{rpm}$ for $10 \mathrm{~min}$ to remove insoluble material. The concentration of proteins was determined by spectrophotometric method using Bradford reagent (Biorad, Hercules, CA, USA) as per protocol provide by the manufacturer and proteins were stored in aliquots at $-80{ }^{\circ} \mathrm{C}$ till further use. Total cellular proteins $(50 \mu \mathrm{g} /$ lane $)$ were separated in 8-12\% polyacrylamide gel and electrotransferred on PVDF membrane (Millipore Corp, USA). The membrane was first probed with primary antibody. These blots were washed, incubated with HRP-anti-mouse IgG secondary antibodies and visualized by Luminol detection kit (Santa Cruz Biotech) and by exposing the blot to KODAK X-Omat films (Kodak India). The membranes were reprobed for $\beta$-actin expression as an internal control. The quantitative densitometric analysis of the bands was performed using Alpha Ease FC version 4.1.0 (Alpha Innotech Corporation, IL). Normalized fold difference in expression of STAT3, pSTAT3 (Y705), HPV16 E6, MMP-2, MMP-9, PTEN and TIMP-3 in each sample was determined by densitometric analysis of each band in comparison to pooled normal sample which was used as control and normalized for input by using $\beta$-actin bands. The working dilution of all primary antibodies was 1:2000 and for secondary antibodies

Table 3 List of primers used for microRNA-21 \& Let-7a qRT-PCR in the study

\begin{tabular}{ll}
\hline Primer name & Primer sequence \\
\hline U6 RT & 5' CGCGCCTGCAGGTCGACAATTAACCCTCACTAAAGGGttgcgtgtcatcc 3' \\
U6 PCR (F) & 5' GTAATACGACTCACTATAGGGAGAAGAGcctgcgcaagg 3' \\
U6 PCR (R) & 5' CGCGCCTGCAGGTCGAC 3' \\
miR-21 RT & 5' CGCGCCTGCAGGTCGACAATTAACCCTCACTAAAGGGtcaacatcagtct 3' \\
miR-21 PCR (F) & 5' GTAATACGACTCACTATAGGGAGAAGAGtagcttatcag 3' \\
miR-21 PCR (R) & 5' CGCGCCTGCAGGTCGAC 3' \\
Let-7a RT & 5' CGCGCCTGCAGGTCGACAATAACCCTCACTAAAGGGaactatacaacct 3' \\
Let-7a PCR (F) & 5' GTAATACGACTCACTATAGGGAGAAGAGtgaggtagtag 3' \\
Let-7a PCR (R) & 5' CGCGCCTGCAGGTCGAC 3'
\end{tabular}

The capital letters indicate universal primers sequence of miRNAs for RT and forward primer of each miR while small letters sequence is specific for the miRNA of interest which binds to the miRNA. The amplicon size for each miR is $90 \mathrm{bp}$ 
it was 1:5000. For $\beta$-actin primary antibody dilution was 1:5000 and for secondary antibody it was 1:10,000.

\section{Reverse transcription-PCR for STAT3 mRNA expression}

Total RNA isolated by mirVana miRNA isolation kit was subjected to reverse transcription using Omniscript RT-PCR kit (Qiagen, Hilden, Germany) to prepare the cDNA as per manufacturer's instructions. Amplification of STAT3 and GAPDH transcripts from the cDNAs was performed as per routine laboratory procedure [1]. Normalized fold difference in expression of STAT3 transcripts in each sample was determined by densitometric analysis of the band in comparison to respective band in normal. Input was normalized by comparing respective GAPDH bands in normal and test lanes.

\section{Statistical analysis}

Quantitative data was described as mean \pm standard error (SE). Kruskal-Wallis test was done to check the significant mean difference. Mann-Whitney test was employed to compare the significant mean difference of microRNAs expression correlation between two groups. $p$ value $<0.05$ was considered significant. SPSS software (version 16.0) was used for all statistical calculations.

\section{Results}

Established cervical cancer cell lines (C33a, SiHa, CaSki, HeLa) and cervical biopsies comprising 23 pre-cancer, 56 cancer lesions and 23 control tissues were examined for presence of HPV infection and their genotypes, the expression level of miR-21, let-7a, STAT3 and pSTAT3 (Y705) in each specimen. Clinicopathological characteristics of specimen and their status of HPV infection is presented in Table 1. PCR-based detection revealed HPV infection in 14 out of 23 cases (61\%) of pre-cancer lesions and 53 out of 56 cases (95\%) of cancer lesions (Table 1). Among these, 12 out of 23 (52\%) pre-cancer and 44 out of 56 (79\%) cancer cases were found to contain HPV16 infection, whereas, only $6(11 \%)$ cancer cases showed HPV18 infection. Cytological as well as molecular evaluation of control tissues from non-malignant cervix revealed 3 cytological normal HPV negative tissues whereas 20 tissues showed cytological changes resembling cervicitis of which one was found HPV16-positive.

\section{miR-21 and let-7a expression in cervical cancer cell lines and tissue biopsies}

Total RNA isolated from cervical cancer cell lines and tissues was subjected to miR-specific qRT-PCR for the analysis of miRNAs expression. RNA from C33a cells and pooled RNA from normal cervical tissues were used as control for semi-quantitative analysis of miRs expression in cell lines and tumor tissues, respectively. Variable level of miR-21 and let-7a were detected among different cervical cancer cell lines irrespective of their type of HPV infection (Fig. 1a). In comparison to HPV-negative C33a cells, HPV-positive SiHa, Caski and HeLa cells showed high level of miR-21. On the other hand, let-7a expression was low in HPV-positive cell lines. miRs expression in normal/control tissues that passed for amplification of internal control U6 (15/23) was uniform except 5 outlier cases ( 3 for miR-21 and 2 for let-7a) and resembled to pooled reference Additional file 1: Figure S1A. Further examination revealed an overexpressed miR-21 in pre-cancer and cervical cancer lesions and its level increased from LSIL to HSIL. Level of miR-21 was higher among tumor tissues from cancer lesions. In contrast, low level of let-7a was detected in cancer tissues compared to the let-7a in pre-cancer and normal control tissues. Among all tissue types, a characteristically high level of let-7a was detected particularly in pre-cancer lesions (Fig. 1b \& c).

Further, miR expression level was examined in tumor tissues of different clinical stages and histopathological grades. Clinical staging was available for 52 out of 56 cancer cases and histopathological grades were available for 44 cancer lesions. Analysis revealed that despite variability, miR-21 level was distinctively high in advanced cervical cancer lesions and the increase was progressive with increase in the severity of the clinical manifestation of cancer lesions in cervical cancer cases (Fig. 1d). As the cervical lesions progressed from early stage I to advanced stage IV, let-7a showed a reciprocal kinetics. Similarly, when miR level were examined in relation to their respective histopathological grades, miR-21 level did show only a marginal difference in well differentiated squamous cell carcinoma (WDSCC) and poorly differentiated squamous cell carcinoma (PDSCC), whereas its level were significantly higher in high grade PDSCC lesions. Higher level of miR-21 was accompanied with low level of let-7a in tissues of PDSCC lesions (Fig. 1e).

\section{Association of STAT3 and pSTAT3 (Y705) with miR-21 and let-7a level in cervical cancer}

We examined association of miR level with expression of total STAT3 and activated STAT3 which is phosphorylated at Y705 residue. Our earlier studies have confirmed that pSTAT3 and STAT3 detected by immunoblotting are transcriptionally active in cervical lesions and cervical cancer cells lines $[1,6]$. Immunoblot analysis of cellular proteins revealed constitutively active STAT3 expression in all cervical cancer cell lines although the degree of expression was variable (Fig. 2a). In contrast to HPV-negative C33a cells, all HPV-positive cells had higher expressions of STAT3 as well as activated form of STAT3 (pSTAT3). Immunoblotting for STAT3 and pSTAT3(Y705) could be performed only in 70 out of 79 cases which revealed a concordant increase in STAT3 and pSTAT3 level in 


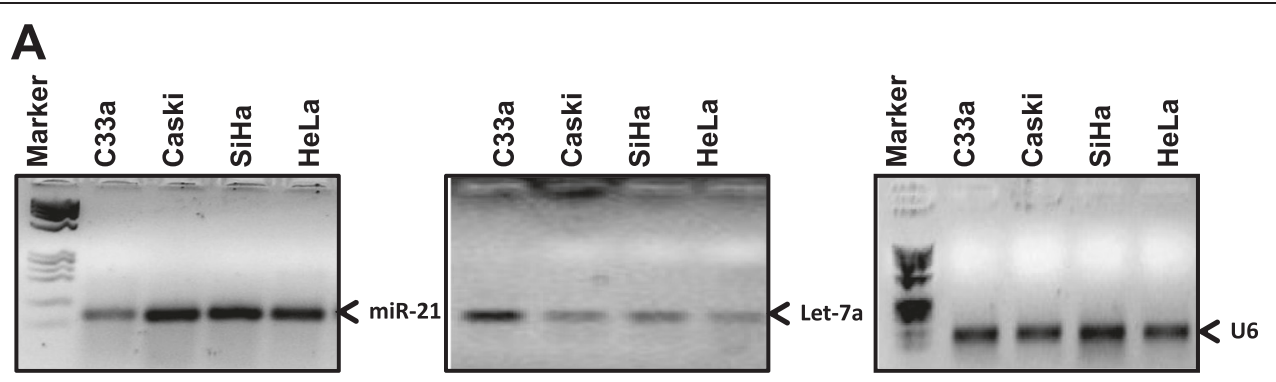

B

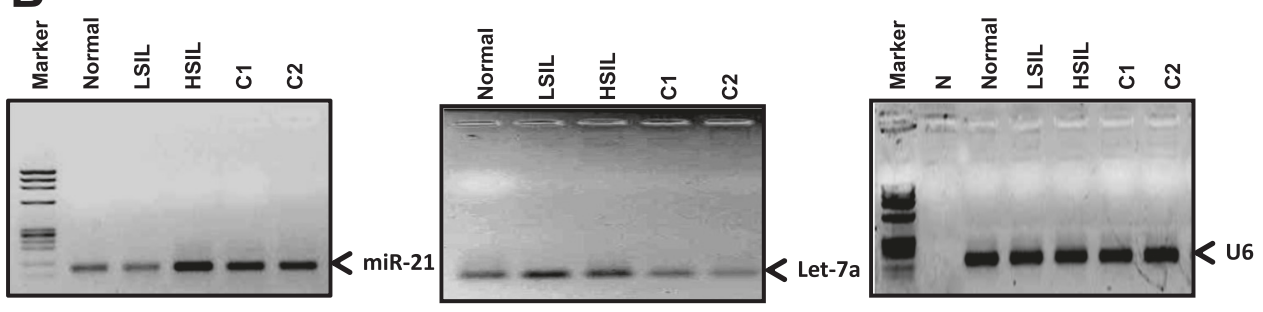

C
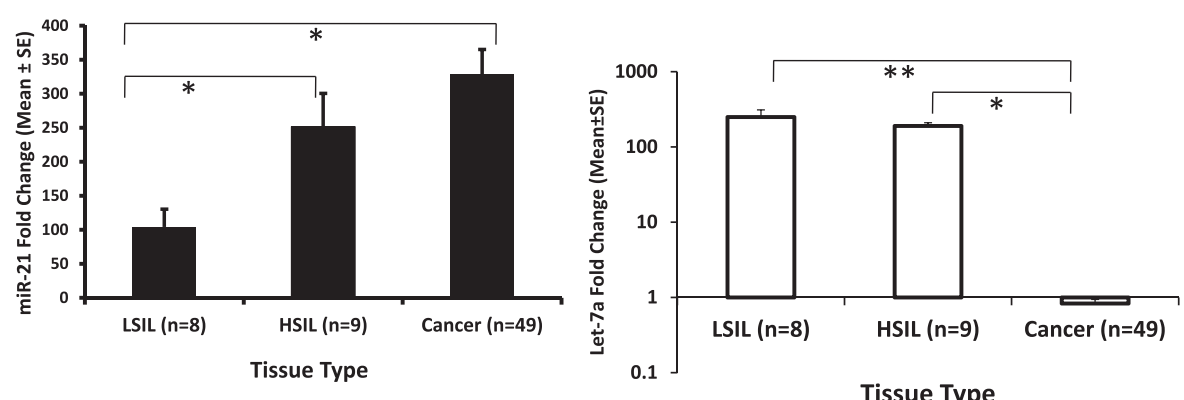

D
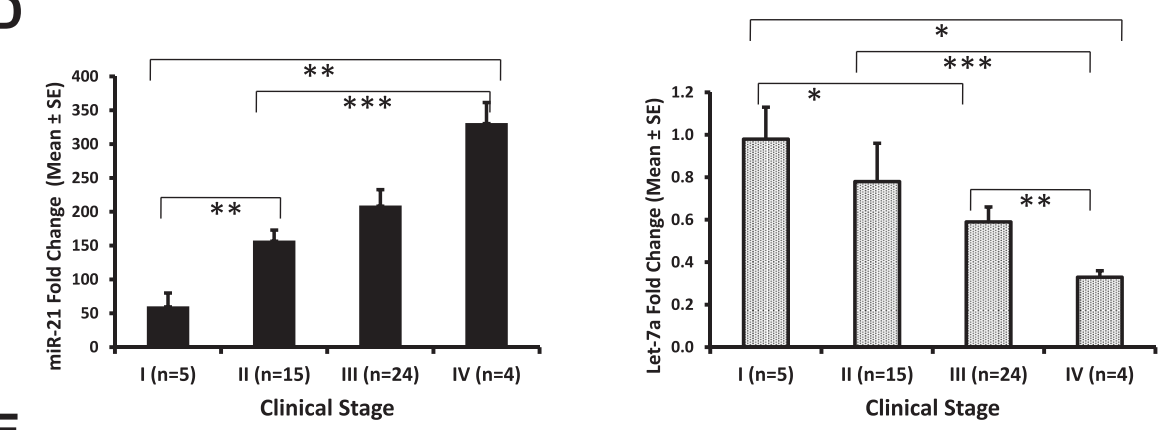

E
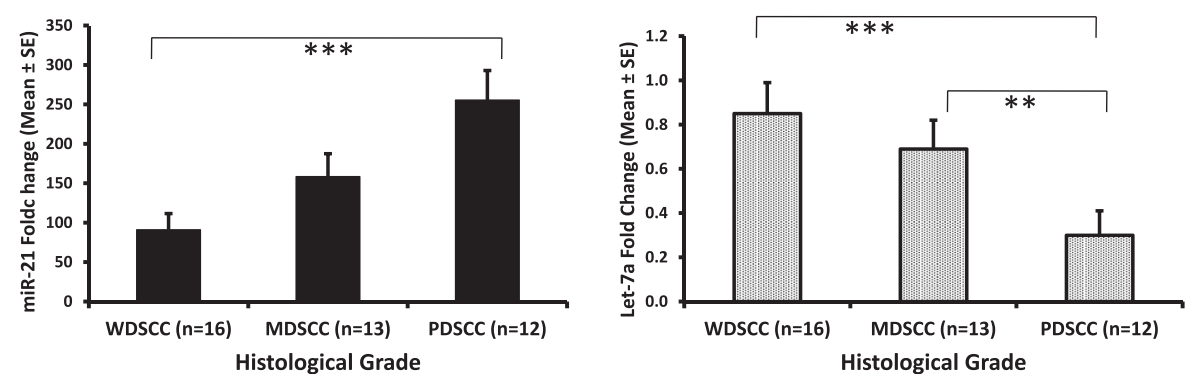

Fig. 1 (See legend on next page.) 
(See figure on previous page.)

Fig. 1 Expression levels of miR-21 and let-7a in cervical cancer cells. a \& $\mathbf{b}$. Representative photograph showing specific amplification of miR-21 and let-7a in quantitative real-time RT-PCR (qRT-PCR) of total RNA isolated from cervical cancer lines, C33a (HPV-), SiHa \& CaSki (HPV16+) and HeLa (HPV18+) (a); or from cervical tissues of normal (N), low grade squamous intra-epithelial lesion (LSIL), high grade SIL (HSIL) and cervical cancer tissues (C1, C2) (b). Amplification of U6 RNA was performed as internal control for input RNA. miR fold change was calculated w.r.t. C33a in case of cell lines or reference pooled RNA from normal tissues. Marker, DX174 Hae III-digested molecular weight marker; N, PCR negative control. c. Cumulative data showing mean \pm S.E. of fold change expression of miR-21 and let-7a in tumor tissues of pre-cancer and cancer lesions. $\mathbf{d} \& \mathbf{e}$. Distribution of miR-21 and let-7a expression in cancer tissues of different clinical stages (d) or in different histopathological grades (e) data showing mean \pm S.E. of fold change expression of miR-21 and let-7a in tumor tissues examined in 3 independent experiments. ${ }^{*} p$ value $<0.05$; ${ }^{* *} p$ value $<0.01$; ${ }^{* *} p$ value $<0.001$. Note: The fold change being reflected in $\mathbf{a} \& \mathbf{b}$ may not corroborate with $\mathbf{c}, \mathbf{d} \& \mathbf{e}$ as they are end products of the $\mathrm{qRT}-\mathrm{PCR}$ run

pre-cancer and cancer lesions indicating that STAT3 expressed in these lesions was predominantly phosphorylated. STAT3 and pSTAT3 level were evaluated densitometrically and examined in association with level of miR-21 and let-7a in corresponding clinical samples (Fig. 2b). Based on the level of their expression and the median value, cervical tissues were classified as having either low or high level of STAT3/pSTAT3 expression in each disease group and their miR level were evaluated accordingly (Fig. 2c \& d). miR-21 level were consistently higher in tissues which expressed high level of STAT3 or pSTAT3 but this correlation was significant only in HSIL and cancer tissues. Opposite to this, let-7a level was significantly lower in cancer tissues which expressed high level of STAT3/ pSTAT3 expression (Additional file 1: Figure S2A). This trend was also observed in pre-cancer tissues but relation was statistically insignificant. Further investigation of STAT3-miR correlation in tissues of different histopathological grades revealed a similar trend of increasing miR-21 along with higher STAT3/pSTAT3 level in PDSCC and concomitant decline in let-7a level (Additional file 1: Figure S2b) but the distribution was not statistically significant.
A
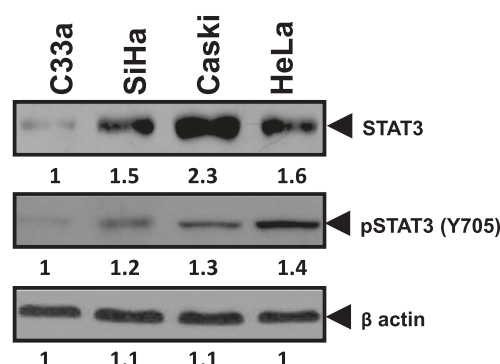

C

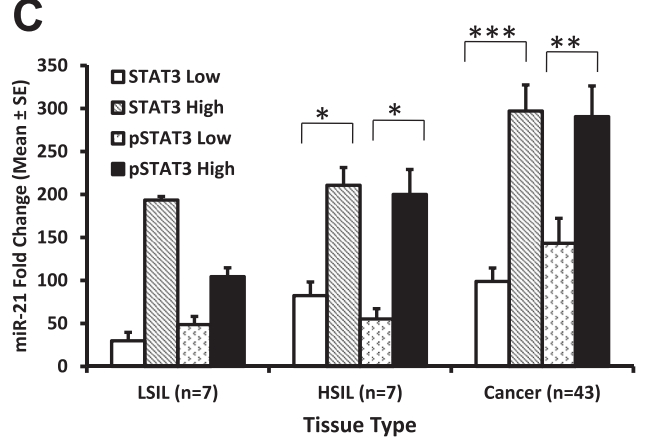

B

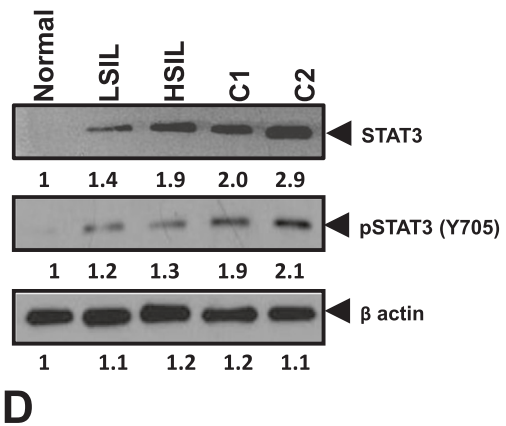

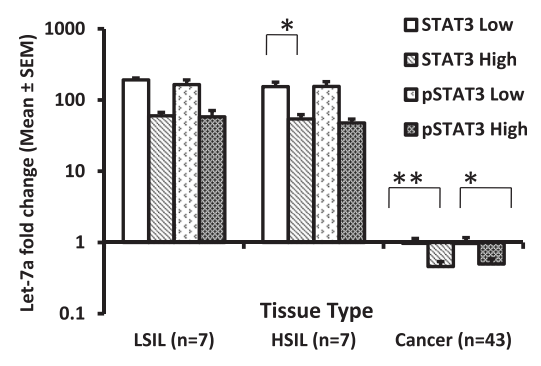

Fig. 2 Association of miR-21 and let-7a with STAT3 expression and activation. a \& b. Representative immunoblots showing expression of total STAT3 and pSTAT3 (Y705) in cervical cancer cell lines (a) and in cervical tissues (b). Total cellular proteins $(50 \mu g)$ isolated from indicated cell lines and cervical tissues were immunoblotted for STAT3, pSTAT3 (Y705) and $\beta$-actin expression by respective antibodies. Values below each blot represent relative difference in levels of indicated proteins w.r.t. normal. Normalized fold difference in expression of STAT3/pSTAT3 band in each tissue type was determined by densitometry as described in Methods in 3 independent experiments. $\mathbf{c} \& \mathbf{d}$. Distribution of miR-21 (c) and let-7a (d) levels (Mean \pm SE) in cervical tissues from pre-cancer and cancer lesions with corresponding STAT3/pSTAT3 protein levels. STAT3/pSTAT3 levels were broadly classified into low or high STAT3/pSTAT3 based on median fold difference in levels of expression of respective protein in each disease group. STAT3 median values were LSIL - 0.97; HSIL - 1.27; Cancer - 2.1. pSTAT3 median values were LSIL - 0.68; HSIL - 1.06; Cancer 1.51. ${ }^{*} p$ value $<0.05 ;{ }^{* *} p$ value $<0.01 ;{ }^{* * *} p$ value $<0.001$ 
Differential expression of miRs in HPV16-positive cases that varied with level of oncogene E6

In order to explore any potential correlation of miR-21 and let-7a with level of viral oncoproteins, we examined and quantitated relative level of E6 expression in HPV16-positive lesion. Antibody used in the study specifically recognized HPV16 E6 and had only weak binding to HPV18 E6 (Fig. 3a). Both the cervical cancer cells lines, SiHa and CaSki expressed prominent E6 level. Therefore, $\mathrm{SiHa}$ cells were used as reference in quantitation of relative E6 level in tumor tissues (Fig. 3b). Despite HPV16 positivity, we observed that level of E6 were much lower in total cellular proteins of all HPV16-positive LSIL and HSIL than cancer tissues. Analysis of miR-21 level with respect to expression of E6 in cervical lesions revealed higher level of miR-21 in high E6 expressing lesions irrespective of the tissue type (Fig. 3c). Similarly, higher level of E6 were accompanied by lower level of let-7a in spite of the fact that let-7a was overexpressed in LSIL and HSIL type of tissues (Fig. 3d).

\section{Expression of downstream targets of STAT3 and their correlation with miR-21 expression in cervical tissues}

As a direct examination of correlation between STAT3mediated upregulation of miR-21 transcription was not feasible in tumor tissues, we therefore measured level of two important mediators MMP-2 and MMP-9 that are transcriptionally regulated by STAT3. Expression of these proteins was detectable but was highly variable among different cell lines (Fig. 4a). MMP-2 and MMP-9 were overexpressed particularly in tissues derived from HSIL and cancer lesions (Fig. 4b). In the subsequent study, we checked the correlation of MMP-2 and MMP9 expression with miR-21 level. Our immunoblotting data of pre-cancer [13] and cancer [38] tissues out of 79 cases in relation to miR-21 level revealed a consistent overexpression of MMP-2 and MMP-9 with high level of miR-21 in all tissue types but this correlation was statistically significant only in cancer tissues (Fig. 4c \& d).

Next, we examined the level of PTEN, and TIMP-3 to assess potential regulatory effect of miR-21 on expression of its target in cervical tumors. Initial immunoblotting

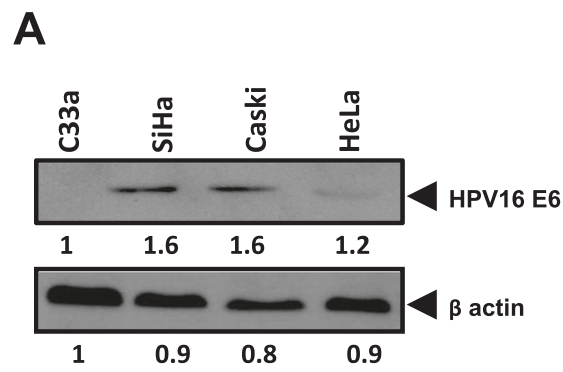

B

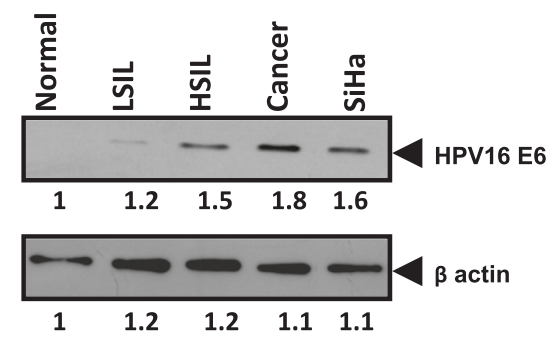

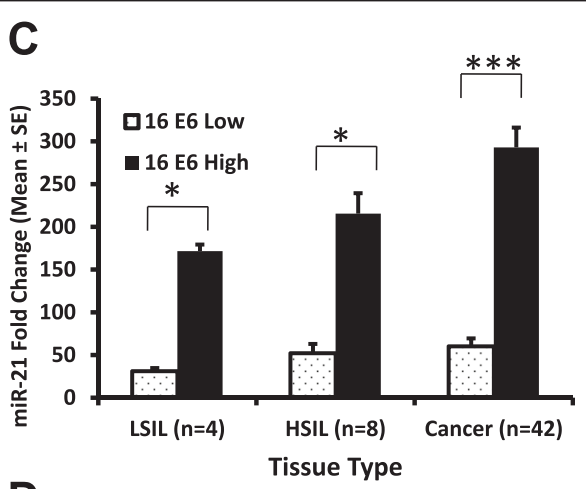

D

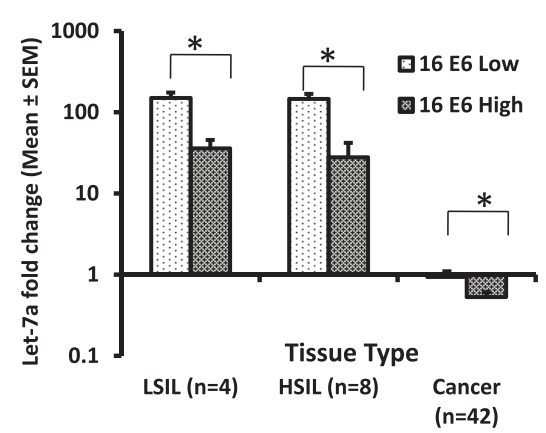

Fig. 3 Association of miR-21 and let-7a with HPV16 E6 expression. a \& b. Representative immunoblots showing levels of HPV16 E6 in indicated cervical cancer cell lines (a) and biopsy tissues (b). $\beta$-actin levels were used as input control. Normalized fold difference in expression of HPV16 E6 band in each tissue type was determined by densitometry as described in Methods. c \& d. Distribution of miR-21 (c) and let-7a (d) levels (Mean \pm SE) in HPV16-positive cervical tissues from pre-cancer and cancer lesions with corresponding E6 protein levels. Relative normalized E6 levels were broadly classified into low or high groups based on median fold difference in HPV16 E6 levels in each disease group. Fold change in E6 expression was measured w.r.t. E6 levels in SiHa cells which were used as reference. HPV16 E6 protein level median values were LSIL - 0.91; HSIL - 0.98; Cancer 1.94. ${ }^{*} p$ value $<0.05 ;{ }^{* *} p$ value $<0.01 ;{ }^{* * *} p$ value $<0.001$ 
A

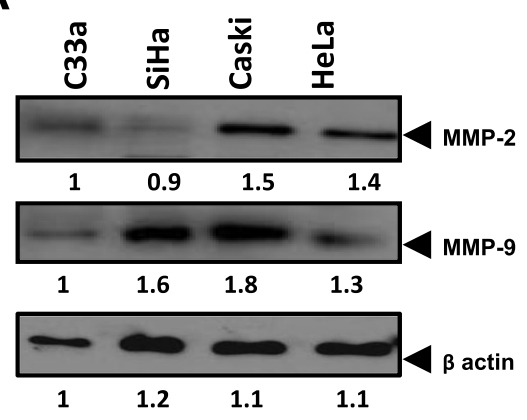

B
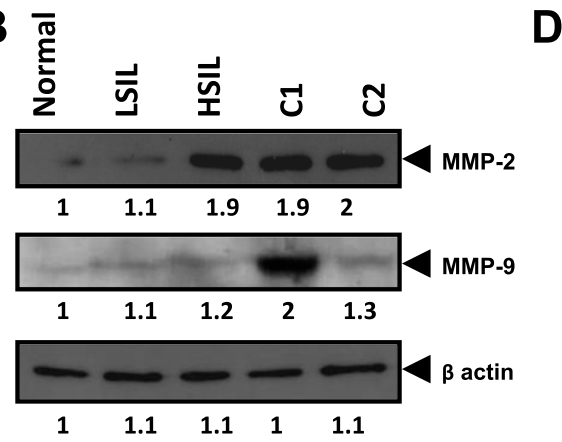

E

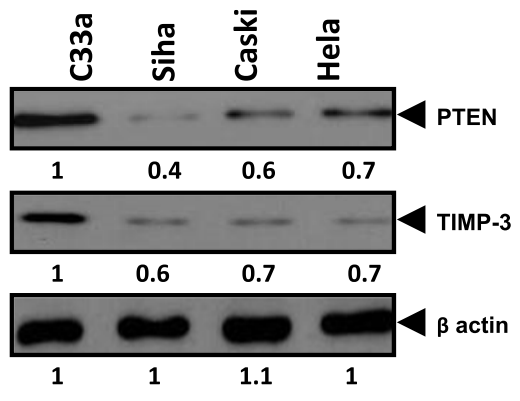

F

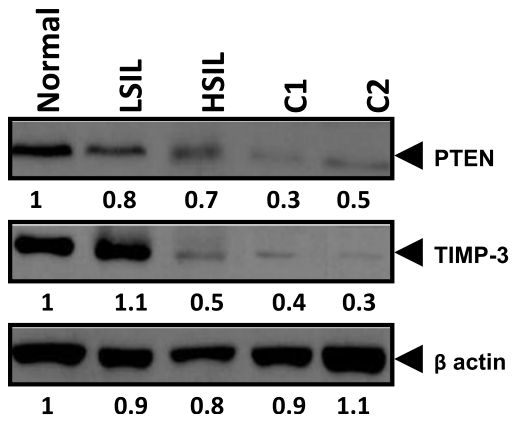

C

D

H
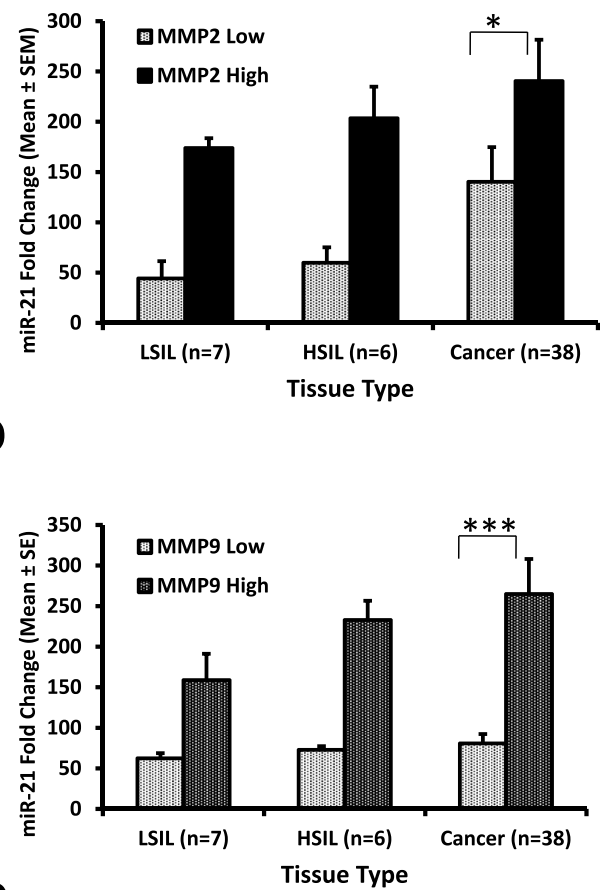

G
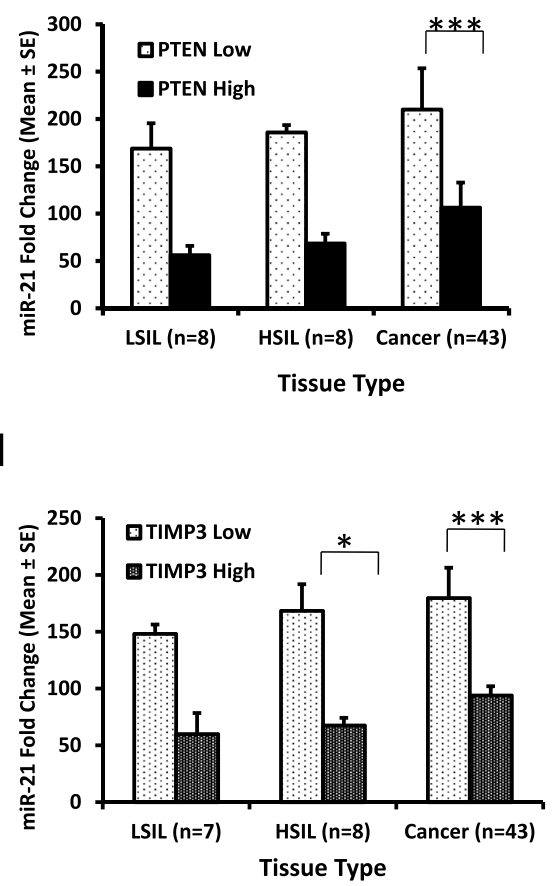

Fig. 4 (See legend on next page.) 
(See figure on previous page.)

Fig. 4 Association of miR-21 levels with STAT3 downstream targets. a \& b. Representative immunoblots showing expression of MMP-2, MMP-9, PTEN and TIMP-3 in indicated cervical cancer cell lines ( $\mathbf{a}, \mathbf{e})$ and cervical tissue biopsies $(\mathbf{b}$, f). Total cellular proteins (50 $\mu \mathrm{g} / \mathrm{lane})$ isolated from cervical cancer cell lines and tissues immunoblotted for MMP-2, MMP-9, PTEN and TIMP-3 expression, blots were subsequently stripped and reprobed with $\beta$-actin which was used as input control. Normalized fold difference in expression of the bands in each tissue type was determined by densitometry as described in Methods in 3 independent experiments. c, $\mathbf{d}, \mathbf{g} \& \mathbf{h}$. Distribution of miR-21 levels (Mean $\pm S E$ ) in cervical tissues from pre-cancer and cancer lesions with corresponding MMP-2, MMP-9, PTEN and TIMP-3 protein levels. Relative normalized protein levels were broadly classified into low or high groups based on median fold difference in respective protein levels in each disease group w.r.t. normal pooled control sample. MMP-2 protein level median values were LSIL - 1.02; HSIL - 1.4; Cancer - 1.56. MMP-9 protein level median values were LSIL 0.98; HSIL - 1.15; Cancer - 1.44. PTEN protein level median values were LSIL - 1.62; HSIL - 1.17; Cancer - 0.67. TIMP-3 protein level median values were LSIL $-1.18 ; \mathrm{HSIL}-1.02$; Cancer $-0.9 .{ }^{*} p$ value $<0.05 ;{ }^{* * *} p$ value $<0.001$

studies to assess the level of expression of PTEN and TIMP-3 were conducted in HPV-positive cervical cancer cell lines $\mathrm{SiHa}, \mathrm{HeLa}$ and Caski which showed low but detectable level of these proteins (Fig. 4e). On the other hand, C33a cells expressed both of these proteins at a comparatively higher level. A high level of both of these proteins was detected in normal cervical tissues which was found gradually diminished in tissues from pre-cancer and cancer lesions (Fig. 4f). Analysis of tumor tissues for expression of these proteins along with miR-21 level revealed low level of PTEN and TIMP-3 in tissues where level of miR-21 were comparatively high (Fig. $4 \mathrm{~g} \& \mathrm{~h}$ ). These correlations were significant particularly in tissues from HSIL and cancer lesions.

\section{Inverse correlation of let-7a level with STAT3 transcripts in cervical tissues}

In the next part of the investigation, we examined effects of let-7a on STAT3 transcripts by performing STAT3specific RT-PCR on cDNA obtained from different tumor tissues and measured the fold change in expression of
STAT3 with respect to normal control (Fig. 5a). STAT3 transcripts were evaluated in 52 out of 79 pre-cancer and cancer cases. HPV-positive HSIL and cervical cancer lesions expressed high level of STAT3 transcripts in concordance with the protein expression as observed earlier (Fig. 5a). The elevated level of STAT3 transcripts were accompanied by a low level of let-7a in cancer cells (Fig. 5b). On the contrary, both LSIL and HSIL in general expressed high let-7a, which was accompanied by low level of STAT3 transcripts. Moreover, differential analysis of let-7a in pre-cancer lesions showed a consistent lower level, which expressed relatively high level of STAT3 transcripts.

\section{Discussion}

Analysis of cervical cancer cell lines and tumor tissues revealed a differential expression of two key microRNAs, miR-21 and let-7a, that correlated with aberrant STAT3 expression and activity. The expression of miR-21 was significantly higher while let-7a showed a low level in cervical cancer tissues. While miR-21 showed direct association, let-7a expression was inversely related to the
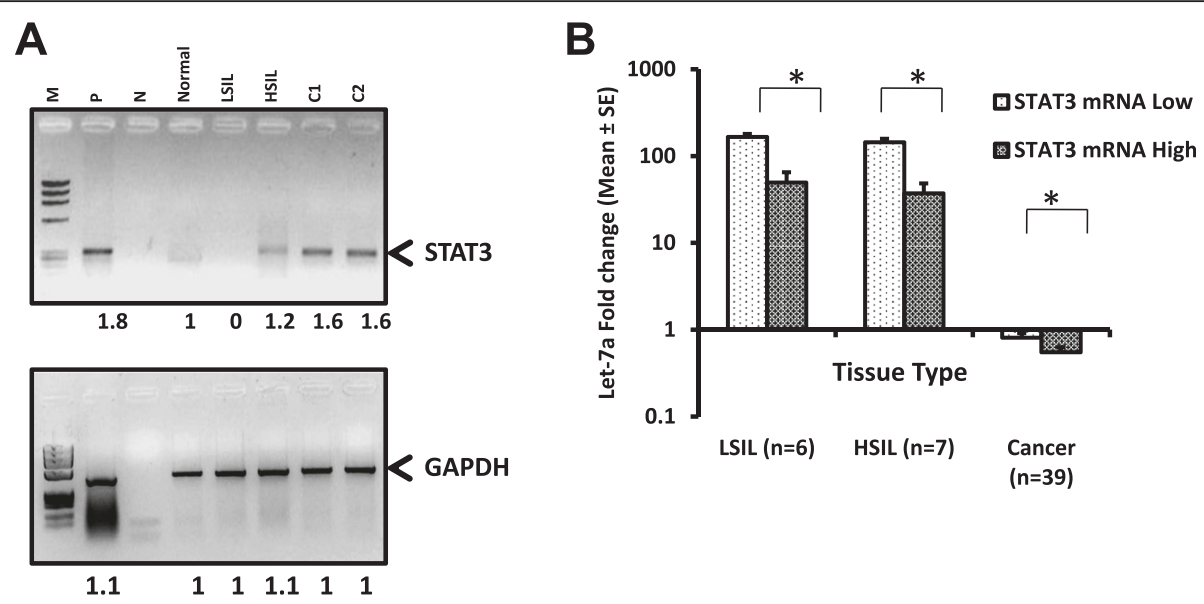

Fig. $\mathbf{5}$ let-7a levels are inversely correlated with STAT3 transcripts. a. Representative photograph showing amplification of STAT3 transcript levels in CDNA of indicated tissue types by RT-PCR (upper panel). GAPDH RT-PCR of respective CDNA was used as input control (lower panel). M: ФX 174 Hae III-digested molecular weight marker; Positive control (P), Negative control (N), Normal, LSIL, HSIL and Cancer (C1, C2) cervical tissue biopsies. Normalized fold difference in expression of the bands in each tissue type was determined by densitometry as described in Methods in 3 independent experiments. b. Distribution of let-7a levels (Mean $\pm S E$ ) in cervical tissues from pre-cancer and cancer lesions with corresponding STAT3 transcript levels. Relative normalized STAT3 mRNA levels were broadly classified into low or high groups based on median fold difference in STAT3 mRNA levels in each disease group. STAT3 mRNA median values were LSIL - 0.65; HSIL - 0.8; Cancer - 1.2. ${ }^{*} p$ value $<0.05 ;{ }^{* * *} p$ value $<0.001$ 
level of total STAT3 pool or its active form (pSTAT3) in HPV-positive cervical cancer lesions. Interestingly, such a reciprocal kinetics was not observed for let-7a particularly in pre-cancer lesions. Typically lesions with LSIL and HSIL cytology overexpressed let-7a. In HPV-positive lesions, miR-21 level corresponded to the level of oncoprotein E6. On the contrary, let-7a level was consistently low in lesions expressing high levels of E6. Low let-7a corresponded with higher STAT3 at mRNA level. Overexpression of miR-21 was found associated with elevated level of other STAT3 regulated gene products MMP-2 and MMP-9 and decreased level of its known target gene products, PTEN and TIMP-3 that negatively regulate STAT3 signaling and its downstream effect via MMPs, respectively.

As a downstream regulatory gene product of STAT3 signaling, miR-21 showed an increased expression with disease progression and severity of the disease in HPV16positive pre-cancer and cancer lesions. Oncogenic role of aberrantly expressed miR-21 have been proposed in cervical carcinogenesis [21-25]. However, its expression was highly variable within the cervical tissues. Our recent observations based on functional silencing of STAT3 signaling in cervical cancer cells by STAT3-specific siRNA or by using specific inhibitors like curcumin or Stattic resulted in loss of cellular miR-21 pool [15]. Clinical data obtained from present investigation along with support from our earlier mechanistic study in an in vitro experimental system strongly suggest transcriptional upregulation of miR-21 through constitutive activity of STAT3 present in cervical cancer cells $[1,3,4,6]$.
Contrary to miR-21, let-7a had high expression level in tissues from pre-cancer lesions but was low or absent in clinically-advanced cancer lesions. Presence of let-7a in copious amounts in HSIL and absence in malignant lesions indicates to a major alteration at genetic or epigenetic level that could be essential for malignant switching and for maintaining the sustained level of STAT3 in malignant cells. However, further studies are needed to understand malignant switching with a particular reference to let-7a. Nevertheless, it can be speculated that oncoprotein E6 may directly or indirectly influence cellular let-7a levels which was not only consistently found negatively correlated to the level of E6 in all spectrum of clinical samples but was found to reappear if E6 was silenced in cervical cells in cultures [15]. Incidentally, silencing E6 has been associated with loss of STAT3 both at mRNA and protein level $[1,6,15]$. Further, transient transfection of let-7a mimics or let-7a precursor which are stable biologically active molecules, directly and effectively silenced the STAT3 expression $[15,26]$.

Further, we analyzed two other STAT3-controlled gene products, MMP-2 and MMP-9. We observed an upregulated expression of these proteins in cervical cancer cell lines and cancer lesions. Their level corresponded with miR-21. Active STAT3 is known to modulate the expression and activity for both MMPs and their inhibitors, TIMPs [39-42]. We also found reduced expression of TIMP-3 particularly in miR-21 overexpressed cancer lesions. Recently, miR-21 has been shown to contribute to invasiveness by downregulation of MMP inhibitor, TIMP3 [43]. Reduced TIMP-3 relieves the inhibition on MMP-2

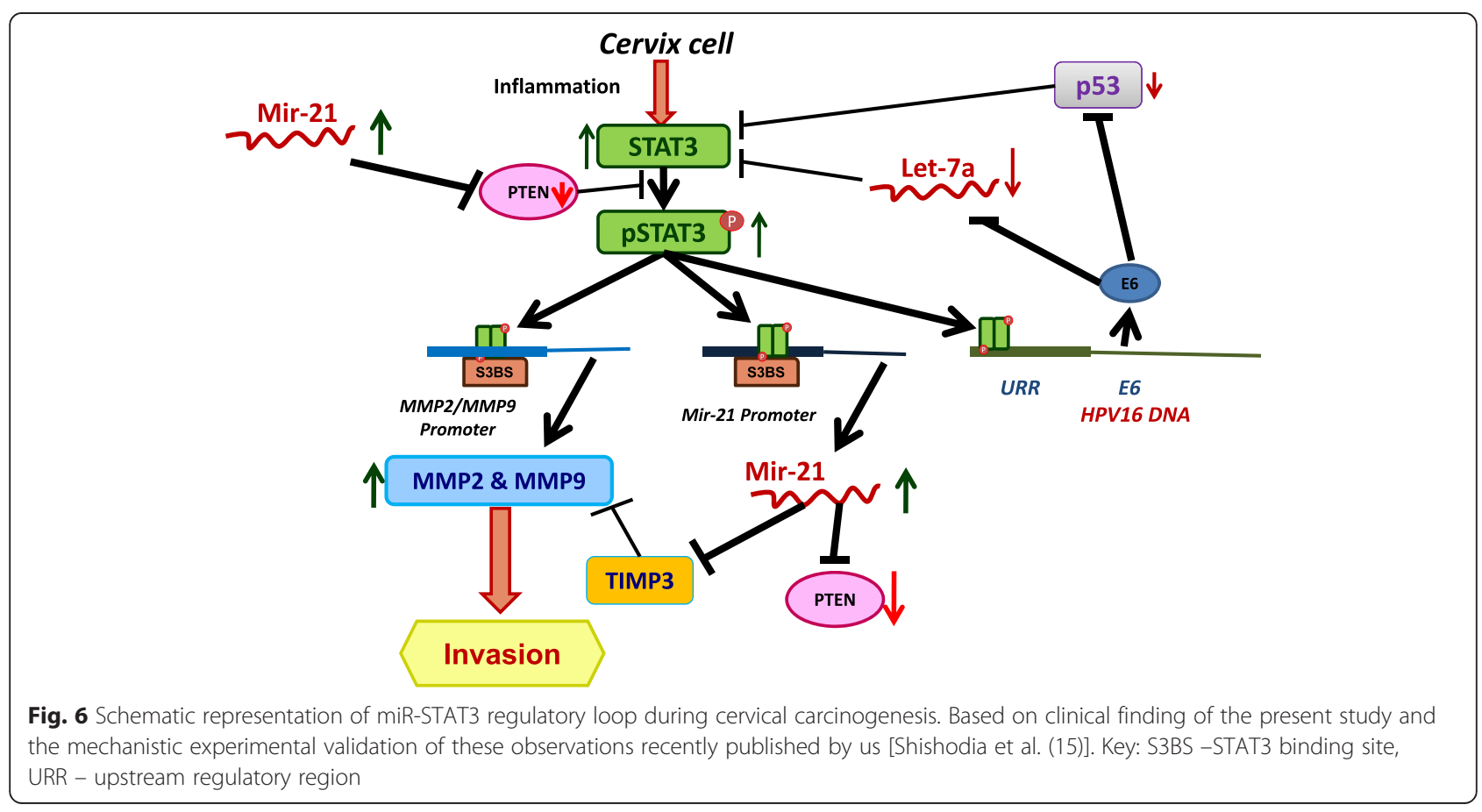


thus leading to activation of MMPs and consequently leads to the invasive behavior of malignant cells [44]. TIMP-3 contains a putative consensus miR-21 binding site that plays a key role in regulating the TIMP-3 transcripts by miR-21 [44]. These observations collectively indicate that aberrant STAT3-mediated events include upregulation of MMPs expression and activity, which could partly be facilitated through activation of miR-21 via suppression of TIMP-3.

In addition to TIMP-3, PTEN which is another molecular target of miR-21 was also found specifically downregulated in miR-21 overexpressing lesions. miR-21 targets PTEN gene through a binding site on 3'-UTR [18]. Low level of PTEN has been reported in cervical cancer [45-47]. Among negative regulators of STAT3, PTEN is responsible for its dephosphorylation and controls overall level of transcriptionally-active phospho (Y705) form of STAT3 [48]. Silencing of miR-21 in cervical cancer cells by miR-21-specific inhibitor or silencing of HPV E6 resulted in intracellular accumulation of PTEN and a corresponding loss of phospholylated form of STAT3 [15]. Thus, these observations collectively suggest a potential role of miR-21 in maintaining high levels of aberrantly activated STAT3 in cervical cancer cells by targeting its negative regulator, PTEN.

Overall, present study suggests higher miR-21 and reduced let-7a expression level are strongly associated with aberrant expression and activation of STAT3 in cervical carcinogenesis and reflects a close link with high risk HPV16 infection having a higher expression of E6 oncoprotein. These clinical findings support our previous report [15] demonstrating experimentally the presence of a functional regulatory loop during cervical carcinogenesis (Fig. 6). Present study, therefore, advocates an operational microRNA-mediated loop that assists constitutively active STAT3 signaling during cervical cancer progression. miR21 and let-7a along with STAT3 collectively form clinically useful set of biomarkers to identify invasive lesions that may be targeted by STAT3 pathway-specific inhibitors for effective management of pre-invasive and invasive cervical cancer lesions.

\section{Additional file}

Additional file 1: Figure S1. A. Representative photograph showing overall distribution of miR-21 and let-7a in tissues from normal controls. There were total five samples which were outliers in this group. B. Representative photograph showincsg miR-21 and let-7a expression levels in cytologicaly normal, cervicitis HPV-negative and cervicitis HPVpositive control tissues. Figure S2. A. Representative photographs showing differential levels of miR-21 and let-7a in tissues from cancer lesions expressing either low or high levels of STAT3/pSTAT3. U6 amplification and $\beta$-actin levels were used as input control. B. Representative photographs showing levels of miR-21 and let-7a in tumor tissues of different histopathological grades along with their corresponding STAT3 levels.

\section{Abbreviations}

HPV: Human papillomavirus; HSIL: High grade squamous intraepithelial lesions; LSIL: Low grade squamous intraepithelial lesions; PBS: Phosphate buffer saline; miR: microRNA; STAT3: Signal transducer and activator of transcription; MMP: Matrix metalloproteinase; PTEN: Phosphatase and tensin homologue; TIMP3: Tissue inhibitor of matrix metalloproteinase-3.

\section{Competing interest}

The authors declare that they have no competing interests.

\section{Authors' contributions}

GS carried out the majority of the experimental work and helped in design of the study, interpretation of the data and in drafting of the manuscript. S Shukla assisted in initial HPV diagnosis and Western blot and designing of the study. YS and S Masaldan assisted in data analysis. S Mehta assisted in procurement of clinical material and clinical evaluation of the study subjects. S Sharma helped in statistical analysis. S Batra assisted in procurement of clinical material and SB performed histopathological evaluation, grading \& diagnosis of clinical samples. BCD and RM participated in the interpretation of the study and critically reviewed the manuscript. ACB conceived and designed the study, participated in the interpretation of the data, drafted the manuscript and critically reviewed and communicated the manuscript. All authors have read and approved the final manuscript.

\section{Acknowledgements}

SRF to GS and SS from DBT. Authors acknowledge Dr. Swaraj Batra, MAMC and Dr. Shweta Tahlan, MAMC in clinical sample collection.

\section{Financial support}

The study was supported by extramural research grants from Department of Biotechnology, Government of India (Grant Support BT/PR10347, 102/IFD/ SAN/PR-1612/2007 \& BT/PR6198/Med/14/758/2005;BT/PR13341/NNT/28/467/ 2009) and intramural funding from ICMR to ACB.

\section{Author details}

'Division of Molecular Oncology, Institute of Cytology and Preventive Oncology, I - 7, Sector -39, Noida 201301, Uttar Pradesh, India. ${ }^{2}$ Division of Cytopathology, Institute of Cytology and Preventive Oncology, I - 7, Sector 39, Noida 201301, Uttar Pradesh, India. ${ }^{3}$ Division of Epidemiology and Biostatistics, Institute of Cytology and Preventive Oncology, I - 7, Sector -39, Noida 201301, Uttar Pradesh, India. ${ }^{4}$ Department of Obstetrics and Gynecology, University College of Medical Sciences and Associated Guru Teg Bahadur Hospital, Shahdara, Delhi, New Delhi, India. ${ }^{5}$ Dr. B.R. Ambedkar Centre for Biomedical Research, University of Delhi, Delhi 110007, New Delhi, India. ${ }^{6}$ Present Address: Louisiana State University Health Sciences Center, Shreveport, LA, USA. PPresent Address: Department of Radiation Oncology, University of Michigan Medical School, Ann Arbor, MI, USA.

Received: 25 February 2015 Accepted: 12 May 2015

Published online: 09 June 2015

\section{References}

1. Shukla S, Shishodia G, Mahata S, et al. Aberrant expression and constitutive activation of STAT3 in cervical carcinogenesis: implications in high-risk human papillomavirus infection. Mol Cancer. 2010;9:282.

2. Sobti RC, Singh N, Hussain S, Suri V, Bharti AC, Das BC. Overexpression of STAT3 in HPV-mediated cervical cancer in a north Indian population. Mol Cell Biochem. 2009;330:193-9.

3. Chen $\mathrm{CL}$, Hsieh FC, Lieblein JC, et al. Stat3 activation in human endometrial and cervical cancers. Br J Cancer. 2007;96:591-9.

4. Takemoto S, Ushijima K, Kawano K, et al. Expression of activated signal transducer and activator of transcription-3 predicts poor prognosis in cervical squamous-cell carcinoma. Br J Cancer. 2009;101:967-72.

5. Kim DJ, Chan KS, Sano S, Digiovanni J. Signal transducer and activator of transcription 3 (Stat3) in epithelial carcinogenesis. Mol Carcinog. 2007;46:725-31.

6. Shukla S, Mahata S, Shishodia G, et al. Functional regulatory role of STAT3 in HPV16-mediated cervical carcinogenesis. PLoS One. 2013;8:e67849.

7. Iliopoulos D, Hirsch HA, Struhl K. An epigenetic switch involving NF-kappaB, Lin28, Let-7 MicroRNA, and IL6 links inflammation to cell transformation. Cell. 2009;139:693-706 
8. Xiang M, Birkbak NJ, Vafaizadeh V, et al. STAT3 Induction of miR-146b Forms a Feedback Loop to Inhibit the NF-kappaB to IL-6 Signaling Axis and STAT3Driven Cancer Phenotypes. Sci Signal. 2014;7:ra11.

9. Garner JM, Fan M, Yang CH, et al. Constitutive activation of signal transducer and activator of transcription 3 (STAT3) and nuclear factor kappaB signaling in glioblastoma cancer stem cells regulates the Notch pathway. J Biol Chem. 2013;288:26167-76.

10. Kohanbash G, Okada H. MicroRNAs and STAT interplay. Semin Cancer Biol. 2012;22:70-5.

11. Hu X, Schwarz JK, Lewis Jr JS, et al. A microRNA expression signature for cervical cancer prognosis. Cancer Res. 2010;70:1441-8.

12. Martinez I, Gardiner AS, Board KF, Monzon FA, Edwards RP, Khan SA. Human papillomavirus type 16 reduces the expression of microRNA-218 in cervical carcinoma cells. Oncogene. 2008;27:2575-82.

13. Zheng ZM, Wang X. Regulation of cellular miRNA expression by human papillomaviruses. Biochim Biophys Acta. 1809;2011:668-77.

14. Reshmi G, Pillai MR. Beyond HPV: oncomirs as new players in cervical cancer. FEBS Lett. 2008;582:4113-6.

15. Shishodia G, Verma G, Srivastava Y, Mehrotra R, Das BC, Bharti AC Deregulation of microRNAs Let-7a and miR-21 mediate aberrant STAT3 signaling during human papillomavirus-induced cervical carcinogenesis: role of E6 oncoprotein. BMC Cancer. 2014;14:996.

16. Loffler D, Brocke-Heidrich K, Pfeifer G, et al. Interleukin-6 dependent survival of multiple myeloma cells involves the Stat3-mediated induction of microRNA-21 through a highly conserved enhancer. Blood. 2007;110:1330-3.

17. Asangani IA, Rasheed SA, Nikolova DA, et al. MicroRNA-21 (miR-21) posttranscriptionally downregulates tumor suppressor Pdcd4 and stimulates invasion, intravasation and metastasis in colorectal cancer. Oncogene. 2008:27:2128-36.

18. Meng F, Henson R, Wehbe-Janek H, Smith H, Ueno $Y$, Patel T. The MicroRNA let-7a modulates interleukin-6-dependent STAT-3 survival signaling in malignant human cholangiocytes. J Biol Chem. 2007;282:8256-64.

19. Si ML, Zhu S, Wu H, Lu Z, Wu F, Mo YY. miR-21-mediated tumor growth. Oncogene. 2007;26:2799-803.

20. Zhu S, Wu H, Wu F, Nie D, Sheng S, Mo YY. MicroRNA-21 targets tumor suppressor genes in invasion and metastasis. Cell Res. 2008;18:350-9.

21. Yao T, Lin Z. MiR-21 is involved in cervical squamous cell tumorigenesis and regulates CCL20. Biochim Biophys Acta. 1822;2012:248-60.

22. Yao Q, Xu H, Zhang QQ, Zhou H, Qu LH. MicroRNA-21 promotes cell proliferation and down-regulates the expression of programmed cell death 4 (PDCD4) in HeLa cervical carcinoma cells. Biochem Biophys Res Commun. 2009;388:539-42

23. Wang X, Tang S, Le SY, et al. Aberrant expression of oncogenic and tumorsuppressive microRNAs in cervical cancer is required for cancer cell growth. PLoS One. 2008;3:e2557.

24. Lui WO, Pourmand N, Patterson BK, Fire A. Patterns of known and novel small RNAs in human cervical cancer. Cancer Res. 2007;67:6031-43.

25. Deftereos G, Corrie SR, Feng Q, et al. Expression of mir-21 and mir-143 in cervical specimens ranging from histologically normal through to invasive cervical cancer. PLoS One. 2011;6:e28423.

26. Wang Y, Lu Y, Toh ST, et al. Lethal-7 is down-regulated by the hepatitis virus $x$ protein and targets signal transducer and activator of transcription 3 . J Hepatol. 2010;53:57-66.

27. Jeong HC, Kim EK, Lee JH, Lee JM, Yoo HN, Kim JK. Aberrant expression of let-7a miRNA in the blood of non-small cell lung cancer patients. Mol Med Report. 2011:4:383-7.

28. Calin GA, Sevignani C, Dumitru CD, et al. Human microRNA genes are frequently located at fragile sites and genomic regions involved in cancers. Proc Natl Acad Sci U S A. 2004;101:2999-3004.

29. Germain D, Frank DA. Targeting the cytoplasmic and nuclear functions of signal transducers and activators of transcription 3 for cancer therapy. Clin Cancer Res. 2007;13:5665-9.

30. Triboulet R, Mari B, Lin $Y L$, et al. Suppression of microRNA-silencing pathway by HIV-1 during virus replication. Science. 2007;315:1579-82.

31. Schroer N, Pahne J, Walch B, Wickenhauser C, Smola S. Molecular pathobiology of human cervical high-grade lesions: paracrine STAT3 activation in tumor-instructed myeloid cells drives local MMP-9 expression. Cancer Res. 2011;71:87-97.

32. Tsareva SA, Moriggl R, Corvinus FM, et al. Signal transducer and activator of transcription 3 activation promotes invasive growth of colon carcinomas through matrix metalloproteinase induction. Neoplasia. 2007;9:279-91.
33. Catterall JB, Carrere S, Koshy PJ, et al. Synergistic induction of matrix metalloproteinase 1 by interleukin-1alpha and oncostatin $M$ in human chondrocytes involves signal transducer and activator of transcription and activator protein 1 transcription factors via a novel mechanism. Arthritis Rheum. 2001;44:2296-310.

34. Gatsios P, Haubeck HD, Van de Leur $E$, et al. Oncostatin M differentially regulates tissue inhibitors of metalloproteinases TIMP-1 and TIMP-3 gene expression in human synovial lining cells. Eur J Biochem. 1996;241:56-63.

35. Korzus E, Nagase H, Rydell R, Travis J. The mitogen-activated protein kinase and JAK-STAT signaling pathways are required for an oncostatin M-responsive element-mediated activation of matrix metalloproteinase 1 gene expression. J Biol Chem. 1997;272:1188-96.

36. Das BC, Sharma JK, Gopalkrishna V, et al. A high frequency of human papillomavirus DNA sequences in cervical carcinomas of Indian women as revealed by Southern blot hybridization and polymerase chain reaction. J Med Virol. 1992;36:239-45.

37. Shukla S, Mahata S, Shishodia G, et al. Physical state \& copy number of high risk human papillomavirus type 16 DNA in progression of cervical cancer. Indian J Med Res. 2014;139:531-43.

38. Mishra A, Bharti AC, Varghese P, Saluja D, Das BC. Differential expression and activation of NF-kappaB family proteins during oral carcinogenesis: Role of high risk human papillomavirus infection. Int J Cancer. 2006;119:2840-50.

39. Apte SS, Olsen BR, Murphy G. The gene structure of tissue inhibitor of metalloproteinases (TIMP)-3 and its inhibitory activities define the distinct TIMP gene family. J Biol Chem. 1995;270:14313-8.

40. Suman P, Shembekar N, Gupta SK. Leukemia inhibitory factor increases the invasiveness of trophoblastic cells through integrated increase in the expression of adhesion molecules and pappalysin 1 with a concomitant decrease in the expression of tissue inhibitor of matrix metalloproteinases. Fertil Steril. 2013;99:533-42.

41. Ghosh A, Pechota A, Coleman D, Upchurch Jr GR, Eliason JL. Cigarette smoke-induced MMP2 and MMP9 secretion from aortic vascular smooth cells is mediated via the Jak/Stat pathway. Hum Pathol. 2015;46:284-94.

42. Xu G, Zhang C, Zhang J. Dominant negative STAT3 suppresses the growth and invasion capability of human lung cancer cells. Mol Med Rep. 2009;2:819-24.

43. Martin Del Campo SE, Latchana N, Levine KM, et al. MiR-21 Enhances Melanoma Invasiveness via Inhibition of Tissue Inhibitor of Metalloproteinases 3 Expression: In Vivo Effects of MiR-21 Inhibitor. PLoS One. 2015;10:e0115919.

44. Gabriely G, Wurdinger T, Kesari S, et al. MicroRNA 21 promotes glioma invasion by targeting matrix metalloproteinase regulators. Mol Cell Biol. 2008:28:5369-80

45. El-Mansi MT, Williams AR. Evaluation of PTEN expression in cervical adenocarcinoma by tissue microarray. Int J Gynecol Cancer. 2006;16:1254-60.

46. Lee JS, Choi YD, Lee JH, et al. Expression of PTEN in the progression of cervical neoplasia and its relation to tumor behavior and angiogenesis in invasive squamous cell carcinoma. J Surg Oncol. 2006;93:233-40.

47. Zhang $\mathrm{Z}$, Joh $\mathrm{K}$, Yatsuki $\mathrm{H}$, et al. Retinoic acid receptor beta2 is epigenetically silenced either by DNA methylation or repressive histone modifications at the promoter in cervical cancer cells. Cancer Lett. 2007; $247: 318-27$

48. Sun S, Steinberg BM. PTEN is a negative regulator of STAT3 activation in human papillomavirus-infected cells. J Gen Virol. 2002;83:1651-8.

\section{Submit your next manuscript to BioMed Central and take full advantage of:}

- Convenient online submission

- Thorough peer review

- No space constraints or color figure charges

- Immediate publication on acceptance

- Inclusion in PubMed, CAS, Scopus and Google Scholar

- Research which is freely available for redistribution 